\title{
Role of prophylactic iron supplements in preventing recurrences of simple febrile seizures in infants: A prospective study
}

\author{
*K Nandhini ${ }^{1}$, A K Shanthi ${ }^{2}$, J Podhini ${ }^{3}$, P Soundararajan ${ }^{4}$
}

Sri Lanka Journal of Child Health, 2021; 50(3): 472-477

\begin{abstract}
Background: An important risk factor for simple febrile seizures (SFS) could be iron deficiency anaemia (IDA). Though SFS are benign, a history of seizures amongst children in their infancy is often associated with increased chances of recurrence.
\end{abstract}

Objectives: To gauge the effectiveness of prophylactic iron and folic acid (IFA) supplementation in maintaining normal iron status (NIS) and to reduce the recurrences of SFS in children aged 6-12 months over 1 year of follow up.

Method: This study recruited 101 children with SFS. Baseline clinical and laboratory investigations were conducted for all the children. Children with NIS were prescribed biweekly IFA supplementation. Mild, moderate and severe IDA were managed using iron therapy, following which, prophylactic IFA supplementation with biannual deworming was piloted for one year. At the end of one year, serum ferritin levels and complete blood counts were assessed and the frequency of SFS episodes were documented. Data analysis was done using Chi-Square test.

Results: Frequency of IDA in the study was $93.1 \%$. After intervention, $63.4 \%$ showed NIS and increased serum ferritin levels. Thus, the iron status improved after supplementing IFA for one year. After one year of IFA supplementation it was noted that $81.2 \%$ of children were void of SFS.

${ }^{1}$ Post-graduate Student, ${ }^{2}$ Professor, ${ }^{3}$ Assistant Professor, ${ }^{4}$ Professor and Head, Department of Paediatrics, Mahatma Gandhi Medical College and Research Institute, Sri Balaji Vidyapeeth (Deemed-to-be University), Puducherry, 607402, India

*Correspondence: nnandys12@gmail.com

https://orcid.org/0000-0002-6496-0217 (Keceived on 31 July 2020: Accepted after revision on 29 September 2020)

The authors declare that there are no conflicts of interest

Personal funding was used for the project.

Open Access Article published under the Creative

Commons Attribution CC-BY (CC) (P) License
Conclusions: Reduced ferritin levels in infants with FS showed significant improvement after biweekly IFA supplementation. Although a reduction in the recurrence of SFS in IDA infants was noted after therapeutic dose supplementation of iron, this reduction was not statistically significant.

DOI: http://doi.org/10.4038/sljch.v50i3.9728

(Key words: Febrile seizures, infant, irondeficiency anaemia).

\section{Introduction}

Simple febrile seizures (SFS) have a global prevalence of $2-5 \%$ in 6 month to 5 year old children and are usually benign ${ }^{1-3}$. The occurrence of SFS in the first year of life escalates the chances of recurrence by $50 \%{ }^{4}$. SFS affects $5-10 \%$ of Indian children ${ }^{5}$. Although SFS do not have any lasting effects, they can lead to complications like aspiration ${ }^{6}$. The episodes by themselves can be agonizing to both parents and the child ${ }^{7}$.

Iron deficiency anaemia (IDA) is considered to be one of the risk factors for $\mathrm{FS}^{8-10}$. It is the commonest nutritional disorder globally ${ }^{11}$. According to the National Family Health Survey-4 of India, IDA has a reported prevalence of $58.4 \%$ in 6-59 month old children ${ }^{9}$. Studies to weigh the potency of prophylactic iron and folic acid (IFA) supplementation in preventing the recurrence of SFS have not yet been documented. Thus, this is a pioneer study to evaluate the effectiveness of prophylactic IFA supplementation in the reduction of recurrence of SFS in children. This prospective study was conducted in children with SFS, under the aegis of Government of India's National Iron Plus Initiative (NIPI).

\section{Method}

This prospective study was carried out at a tertiary health care centre, from December 2017 to August 2019. This study recruited 101 infants with SFS from 6 to 12 months of age. There were no dropouts. Infants with atypical or complex FS at presentation and those diagnosed with anaemia due to other aetiologies like haemolytic anaemia were not considered for the study. Additionally, children whose parents refused to provide consent were also excluded from the study. 
A comprehensive case history was recorded in all the recruited children with pertinent questions such as age at the first episode of SFS and a history of SFS in parents, siblings or first-degree relatives. Blood investigations such as complete blood count $(\mathrm{CBC})$ and serum ferritin levels were done two weeks after the acute febrile illness settled. CBC was analysed using automated cell analyser and serum ferritin by fully automated bi-directionally interfaced chemiluminescent immunoassay.

Infants with normal values of haemoglobin $(\mathrm{Hb})$ $(\geq 11 \mathrm{mg} / \mathrm{dl})$, mean corpuscular volume (MCV) $(<87 \mathrm{fl})$, mean corpuscular haemoglobin $(\mathrm{MCH})$ $(<29 \mathrm{pg})$, mean corpuscular haemoglobin concentration $(\mathrm{MCHC})(<34 \mathrm{~g} / \mathrm{dl})$ and serum ferritin $(<12 \mathrm{ng} / \mathrm{ml}$ for males and $<30 \mathrm{ng} / \mathrm{ml}$ for females) were considered as being in normal iron status $(\mathrm{NIS})^{12}$. Infants with normal $\mathrm{Hb}$ values but low $\mathrm{MCV}, \mathrm{MCH}, \mathrm{MCHC}$ and/or serum ferritin were considered as having sub-clinical iron deficiency (SID). Infants with low $\mathrm{Hb}, \mathrm{MCV}$, $\mathrm{MCH}, \mathrm{MCHC}$ and serum ferritin were considered to have IDA. According to the World Health Organisation (WHO) classification of anaemia, infants were classified into mild, moderate and severe IDA based on their $\mathrm{Hb}$ values. Infants with $\mathrm{Hb}$ values of $10-10.9 \mathrm{~g} / \mathrm{dl}$ were considered as having mild IDA, infants with $\mathrm{Hb}$ values of 7-9.9 $\mathrm{g} / \mathrm{dl}$ were considered as having moderate IDA and infants with $\mathrm{Hb}$ values of $<7 \mathrm{~g} / \mathrm{dl}$ were considered as having severe IDA $^{11}$.

For infants in the NIS group, bi-weekly IFA (supplied in $100 \mathrm{ml}$ bottle, $1 \mathrm{ml}$ containing $20 \mathrm{mg}$ of elemental iron and $100 \mathrm{mcg}$ of folic acid in syrup form given 1 hour after meal) was instituted for one full year as per the NIPI. Biannual deworming was done. For infants in the SID group, therapeutic doses of iron $(4 \mathrm{mg} / \mathrm{kg} /$ day of elemental iron, daily 1 hour after the meal) was instituted for 3 months to correct the existing IDA. This was followed by supplementing them with
IFA bi-weekly for one full year along with biannual deworming. For all the infants with existing IDA, correction with therapeutic doses of iron $(4 \mathrm{mg} / \mathrm{kg} /$ day of elemental iron, daily 1 hour after meal) was instituted. For patients with mild, moderate and severe IDA, the therapy was instituted for a duration of 4,5 and 6 months respectively. This was followed by instituting a therapeutic dose in these infants with the regimen similar to that provided for the NIS group after blood test confirmation.

Throughout the study period, the sum of febrile episodes and the SFS episodes was documented in all children by periodic follow up. CBC and serum ferritin were done at the end of one year of iron prophylaxis.

Ethical issues: Ethical clearance was obtained from the Institutional Ethics Committee of Mahatma Gandhi Medical College and Research Institute, Sri Balaji Vidyapeeth (Deemed-to-be University), Puducherry, India (No. PG Dissertation/ 12/ 2017/ 97). Informed written consent was obtained from the parents

Statistical analysis: Data was analysed using SPSS version 22. The distribution of infants based on the grades of anaemia and recurrence of SFS with respect to the grades of anaemia were analysed using Chi-square test. Variables such as gender distribution, level of $\mathrm{Hb}$, level of ferritin before and after treatment, mean values of the RBC indices of the study population before and after the intervention were compared using the independent t-test. Differences were considered significant at $\mathrm{p}<0.05$.

\section{Results}

Among the 101 eligible participants of the study, $67.3 \%$ were males and $32.7 \%$ were females. Figure 1 shows the anaemia grade distribution in the study population before and after intervention.

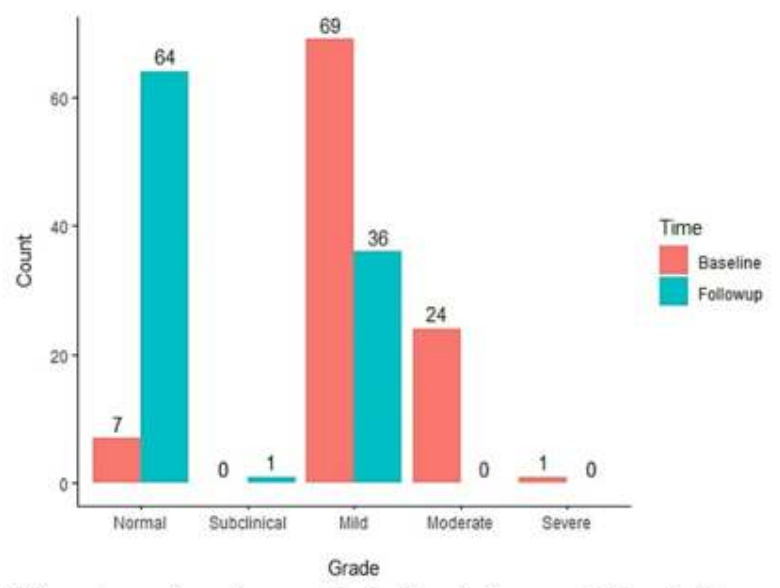

Figure 1: Comparing different grades of anaemia in the study population before and after intervention 
A majority of the population showed normal iron status (NIS), indicating the improvement in anaemia status after intervention. In the study group, 7 (6.9\%) children had NIS, $69(68.3 \%)$ had mild IDA, 24 (23.8\%) had moderate IDA and 1 (1\%) had severe IDA, with an overall prevalence of IDA at $93.1 \%$.

Following prophylactic iron supplementation, a majority of the infants $(63.4 \%)$ showed NIS with a marked upsurge in serum ferritin and $\mathrm{Hb}$ values on one year of follow-up. A majority of children $(81.2 \%)$ had no recurrence of seizure, $12.9 \%$ had recurrence of SFS and $5.9 \%$ had recurrences as complex FS or epilepsy was also observed. It was also noted that there was no recurrence in the group with NIS and $33 \%$ and $75 \%$ of the recurrences were noted in children in the mild and moderate IDA group respectively.

The serum ferritin level and red blood cell (RBC) indices before and after intervention were also noted in this study. Figure 2 shows a strip chart of the distribution of these parameters before and after intervention. It demonstrates a marked increase in serum ferritin levels and $\mathrm{Hb}$ values indicating the improvement in anaemia status. The differences in the RBC indices before and after intervention with respect to $\mathrm{Hb}(p<2.2$, e-16), $\mathrm{MCH}(p=5.63 \mathrm{e}-08)$, $\operatorname{MCHC}(p=0.02873)$ and ferritin $(p<2.2$, e-16) were significant but not with respect to $\mathrm{MCV}$ $(p=0.4721)$.

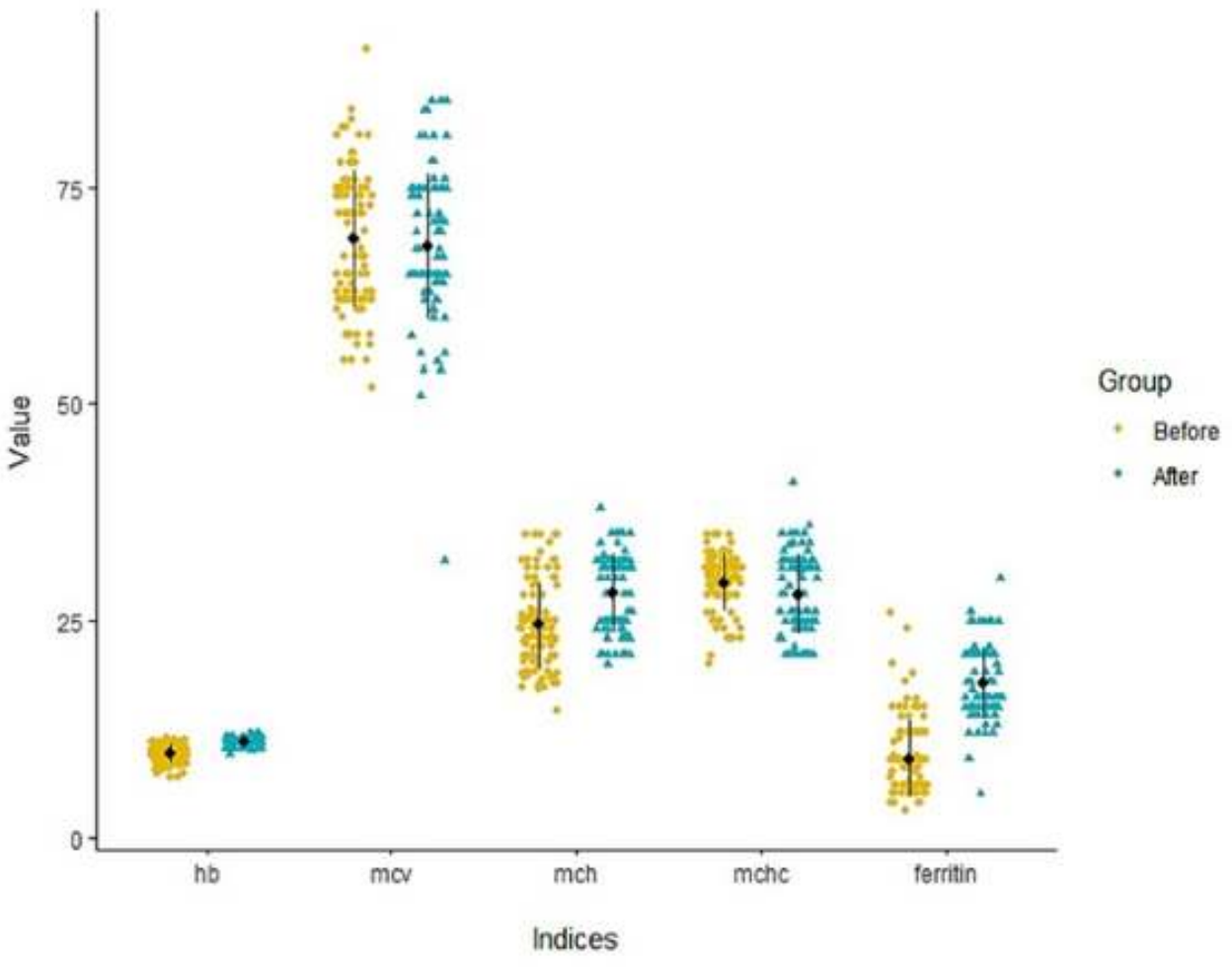

Figure 2: Distribution of RBC indices before and after intervention

Table 1 compares the recurrence of the febrile episode with the grade of anaemia after a year of follow up following the therapeutic regimen in infants. It can be observed that the children with
NIS had no recurrence of SFS. A proportional rise in the frequency of seizure episodes was observed with the increase in the severity of anaemia. However, the difference was insignificant $(p>0.05)$.

Table 1: Recurrences of simple febrile seizure in relationship to grades of anaemia

\begin{tabular}{|c|c|c|c|}
\hline \multirow[t]{2}{*}{ Grade of anaemia } & \multicolumn{2}{|c|}{ Episodes of recurrence of febrile seizure $(n=13)$} & \multirow[b]{2}{*}{$p$} \\
\hline & $\begin{array}{c}\text { One } \\
\text { Number }(\%)\end{array}$ & $\begin{array}{c}\text { More than one } \\
\text { Number (\%) }\end{array}$ & \\
\hline Normal & $0(0)$ & $0(0)$ & \multirow{5}{*}{0.41} \\
\hline Mild & $03(23.1)$ & $01(7.7)$ & \\
\hline Moderate & $08(61.5)$ & $01(7.7)$ & \\
\hline Severe & $0(0)$ & $0(0)$ & \\
\hline Total & $11(84.6)$ & $02(15.4)$ & \\
\hline
\end{tabular}




\section{Discussion}

SFS is a prevalent health issue in infants and has a close association with IDA $^{13-16}$. Due to an enhanced prevalence of IDA in children less than 5 years of age, the Government of India has established the NIPI. This programme caters to the iron supplementation of the pregnant, lactating women as well as children in the age range of 6 months to 19 years. It provides biweekly IFA supplementation with age appropriate deworming for the child. For children of 6 to 60 months age range, a regime of $1 \mathrm{ml}$ of iron and folic acid syrup containing $20 \mathrm{mg}$ of elemental iron and $100 \mathrm{mcg}$ of folic acid is given biweekly. The deworming programme is carried out for children of age 12 months and above by the Accredited Social Health Activist /Auxiliary Nurse Midwife ${ }^{17}$. Though an umpteen number of studies consider IDA as a crucial aetiological factor in the recurrence of SFS in children, there is a scarcity of studies that examine the efficacy of prophylactic IFA supplementation in the inhibition of recurrence of episodes of SFS. Hence, this study tries to fill this lacuna.

Among the 101 infants with SFS, 67.3\% were male and $32.7 \%$ were female. This male preponderance is also seen in a study by Ghasemi $\mathrm{F}$, et $a l^{15}$ but an analytical case study done by Fallah et $a l^{16}$ showed no statistical difference in terms of sex and concluded that both male and female children were equally affected by FS. In the current study, IDA prevalence was $93.1 \%$. In studies by Ghasemi et $a l^{15}$, Fallah $\mathrm{R}$, et $a l^{16}$ and Kwak BO, et al ${ }^{17}$ IDA prevalence was between 35 $45 \%$. One possible explanation for the higher percentage of IDA in our study is that India is a developing country and $58.4 \%$ of the Indian population have IDA. The prevalence of anaemia is much higher in developing countries when compared to developed countries owing to poor nutritional intake. Thus, the increased occurrence of IDA in our study indicates the nutritional status of our population and the need for treatment. Daoud AS, et $a l^{14}$ evaluated the significance of iron status as a possible risk factor. In their study the mean serum ferritin levels in the cases was $29.5 \mathrm{mcg} / \mathrm{L}$, much lower than the $53.5 \mathrm{mcg} / \mathrm{L}$ in the controls. A study by Vaswani RK, et al ${ }^{18}$ had similar findings. In contrast, Bidabadi $\mathrm{E}$, et $a l^{13}$ and Amirsalari $\mathrm{S}$, et $a l^{19}$ reported no significant difference in IDA in children with or without FS.

A study conducted by Daoud AS, et $a l^{14}$ comparing children with and without FS showed that $\mathrm{Hb}, \mathrm{MCV}$ and $\mathrm{MCH}$ were also lower in children with FS compared to children without FS, but difference was not statistically significant $(p>0.05)$, which was attributed to the smaller sample size employed in the study. But in contrast the study conducted by Ghasemi $\mathrm{F}$, et $a l^{15}$, there was no significant difference among the RBC indices between the two study groups $(p>0.05)$. These studies suggested evaluation of these indices after iron supplementation. However, the RBC indices studied before and after intervention in our study showed significant changes in $\mathrm{Hb}, \mathrm{MCH}$ and MCHC and ferritin levels $(p<0.05)$ but not in $\operatorname{MCV}(p>0.05)$.

The highlight of our study was the low attrition rate. This facilitated a comprehensive study of the NIPI organized by the Government of India. Following prophylactic iron supplementation, $63.4 \%$ of the infants showed NIS with a marked increase in $\mathrm{Hb}$ values and serum ferritin and 81.2\% of children had no recurrence of seizure after one year of follow-up. In a study by Leung AK et al $30-40 \%$ of children with a FS had a recurrence during early childhood. The American Academy of Paediatrics quantified that children who develop FS at an age less than one year to have a $50 \%$ chance of recurrence in the second year of life $\mathrm{e}^{20}$. In our study, the recurrence risk was low in comparison to the previous studies, which indicates that the correction of anaemia in children would have aided in diminishing the recurrence of SFS in children. However, there was no statistical significance $(p>0.05)$. This can be attributed to the small sample size, which was a major limitation of this study. A larger, multi-centre trial would better elicit a relationship between prophylactic IFA and recurrence of SFS. Another limitation of this study was the limited period of follow up (1 year). An extensive research should be done with a larger sample size. A control group would have helped in strengthening the association of prophylactic iron supplementation to the reduction in recurrence of FS. Due to ethical issues and not assessing the compliance in our study, control group was not included in our study.

\section{Conclusions}

Reduced ferritin levels in infants with FS showed significant improvement after bi-weekly IFA supplementation. Although a reduction in the recurrence of SFS in IDA infants was noted after therapeutic dose supplementation of iron, this reduction was not statistically significant.

\section{References}

1. Leung AK, Hon KL, Leung TN. Febrile seizures: an overview. Drugs Context 2018; 7:212536.

https://doi.org/10.7573/dic.212536

PMid: 30038660 PMCid: PMC6052913

2. Berg AT, Shinnar S, Shapiro ED, Salomon ME, Crain EF, Hauser WA. Risk factors 
for a first febrile seizure: a matched casecontrol study. Epilepsia 1995; 36: 334-41. https://doi.org/10.1111/j.15281157.1995.t b01006.x

PMid: 7541745

3. Berg AT. Febrile seizures and epilepsy: the contributions of epidemiology. Paediatric and Perinatal Epidemiology 1992; 6:145-52.

https://doi.org/10.1111/j.13653016.1992.t b00756.x

PMid: 1584717

4. Dougherty D, Duffner PK, Baumann RJ, Berman P, Green JL, Schneider $\mathrm{S}$ et al. Febrile seizures: Clinical practice guideline for the long-term management of the child with simple febrile seizures. Pediatrics 2008; 121(6):1281-6. https://doi.org/10.1542/peds.2008-0939 PMid: 18519501

5. Paul SP, Seymour M, Flower D, Rogers E. Febrile convulsions in children. Nursing Children and Young People 2015; 27:145.

https://doi.org/10.7748/ncyp.27.5.14.s16

PMid: 26059584

6. Sadleir LG, Scheffer IE. Febrile seizures. British Medical Journal 2007; 334:30711.

https://doi.org/10.1136/bmj.39087.691817

.AE

PMid: 17289734 PMCid: PMC1796669

7. Waruiru C, Appleton R. Febrile seizures: an update. Archives of Disease in Childhood 2004; 89: 751-6.

https://doi.org/10.1136/adc.2003.028449

PMid: 15269077 PMCid: PMC1720014

8. Kobrinsky NL, Yager JY, Cheang MS, Yatscoff RW, Tenenbein M. Does iron deficiency raise the seizure threshold? Journal of Child Neurology 1995; 10:1059.

https://doi.org/10.1177/088307389501000 207

PMid: 7782598

9. Pisacane A, Sansone R, Impagliazzo N, Coppola A, Rolando P, D'Apuzzo A, et al. Iron deficiency anaemia and febrile convulsions: case-control study in children under 2 years. British Medical Journal 1996; 313(7053): 343.

https://doi.org/10.1136/bmj.313.7053.343

PMid: 8760744 PMCid: PMC2351736
10. Kumari PL, Nair MKC, Nair SM, Kailas $\mathrm{L}$, Geetha S. Iron deficiency as a risk factor for simple febrile seizures--a case control study. Indian Pediatrics 2012; 49: 17-9.

https://doi.org/10.1007/s13312-012-00086

PMid: 21719928

11. WHO. Haemoglobin concentrations for the diagnosis of anaemia and assessment of severity. Vitamin and Mineral Nutrition Information System. Geneva, World Health Organization, 2011. Available from:

https://apps.who.int/iris/bitstream/handle/1 0665/85839/WHO_NMH_NHD_MNM_1 1.1_eng.pdf?ua $=1$ (Accessed on $30 \mathrm{March}$ 2020)

12. Sarma PR. Red Cell Indices. In: Walker HK, Hall WD, Hurst JW, editors. Clinical Methods: The History, Physical, and Laboratory Examinations. 3rd edition. Boston: Butterworths; 1990. Chapter 152. Available from:

https://www.ncbi.nlm.nih.gov/books/NBK $260 /$

13. Bidabadi E, Mashouf M. Association between iron deficiency anaemia and first febrile convulsion: A case-control study. Seizure 2009; 18: 347-51.

https://doi.org/10.1016/j.seizure.2009.01.0 08

PMid: 19223207

14. Daoud AS, Batieha A, Abu-Ekteish F, Gharaibeh N, Ajlouni S, Hijazi S. Iron status: a possible risk factor for the first febrile seizure. Epilepsia 2002; 43: 740-3. https://doi.org/10.1046/j.15281157.2002.3 2501.x

PMid: 12102677

15. Ghasemi F, Valizadeh F, Taee N. Irondeficiency anaemia in children with febrile seizure: A case-control study. Iranian Journal of Child Neurology 2014; 8: 3844.

16. Fallah R, Tirandazi B, Ferdosian F, Fadavi N. Iron deficiency and iron deficiency anemia in children with first attack of seizure and on healthy control group: a comparative study. Iranian Journal of Child Neurology 2014; 8: 1823. 
17. Kwak BO, Kim K, Kim S-N, Lee R. Relationship between iron deficiency anaemia and febrile seizures in children: A systematic review and meta-analysis. Seizure 2017; 52: 27-34.

https://doi.org/10.1016/j.seizure.2017.09.0 09

PMid: 28957722

18. Vaswani RK, Dharaskar PG, Kulkarni S, Ghosh K. Iron deficiency as a risk factor for first febrile seizure. Indian Pediatrics 2010; 47: 437-9. https://doi.org/10.1007/s13312-010-00808

PMid: 19736364
19. Amirsalari S, Doust ZTK, Ahmadi M, Sabouri A, Kavemanesh Z, Afsharpeyman $\mathrm{S}$, et al. Relationship between iron deficiency anaemia and febrile seizures. Iranian Journal of Child Neurology 2010; 4:27-30.

20. Dougherty D, Duffner PK, Baumann RJ, Berman P, Green JL, Schneider S et al. Febrile seizures: Clinical practice guideline for the long-term management of the child with simple febrile seizures. Pediatrics 2008; 121(6): 1281-6. https://doi.org/10.1542/peds.2008-0939 PMid: 18519501 